\title{
Pneumocephalus as a Cause of Postoperative Headache
}

Yasin Yıldız, Mine Kayacı Yıldız, Serkan Emre Eroğlu

Clinic of Emergency Medicine, Ümraniye Training and Research Hospital, Istanbul, Turkey

A 53-year-old woman presented to our emergency department with headache 7 days after an endoscopic endonasal skull base surgery with a transnasal transsphenoidal approach for pituitary adenoma. Clinical examination at the time of admission revealed normal findings; her Glasgow coma scale was 15 and all other vital signs were normal. There was no focal neurological deficit on central nervous system examination. Noncontrast head CT demonstrated bifrontal and convexial (intrahemispheric) intracranial air, also known as pneumocephalus (-1000 Hounsfield units), on the bone window. There was no midline shift (Figure 1-3). She was referred to the neurosurgery clinic and admitted to the clinic for repair surgery. Three days later, she underwent duraplasty and lumbar drainage.

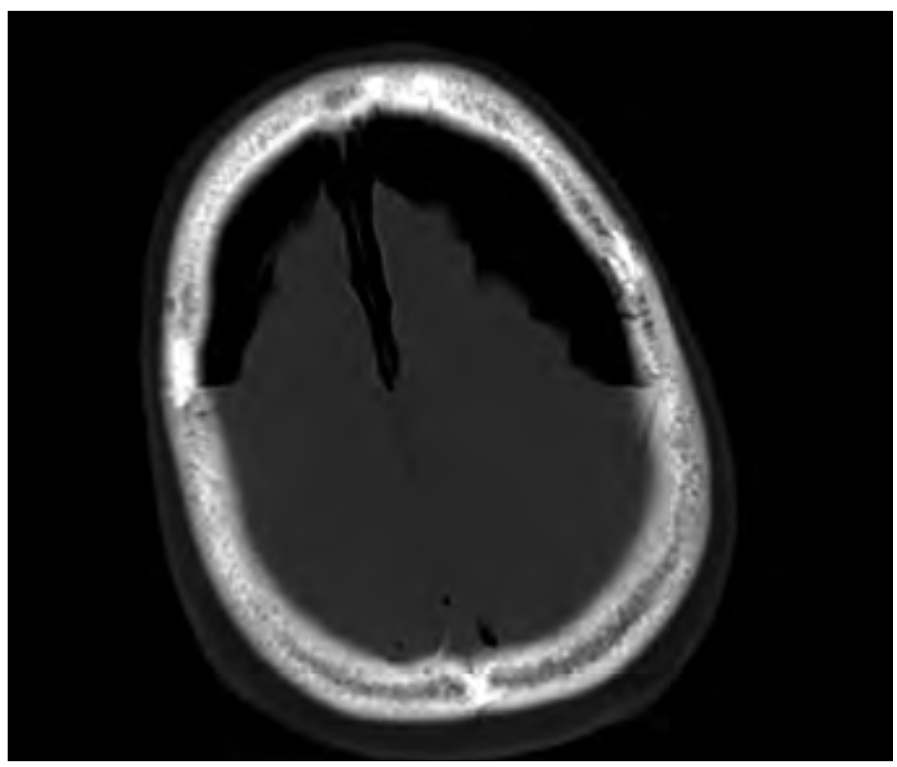

Figure 1. Bifrontal and intrahemispheric pneumocephalus
The presence of gas or air within the cranial cavity is called pneumocephalus. It is usually associated with surgical interventions through the skull or traumatic injury. Serious clinically morbidity rarely occurs in case of pneumocephalus (1). Postoperative pneumocephalus in the frontal or intraventricular locations is rarely associated with postoperative cerebrospinal fluid (CSF) leak. However, pneumocephalus in the interhemispheric fissure, convexity, and parasellar/sellar/perimesencephalic areas is usually related to a postoperative CSF leak (2).

In case of tension pneumocephalus, there is a one-way valve mechanism that draws air into the skull. A serious intracranial mass effect can occur (1). It may result in altered mental status, generalized convulsions with/without focal signs, restlessness, or cardiac

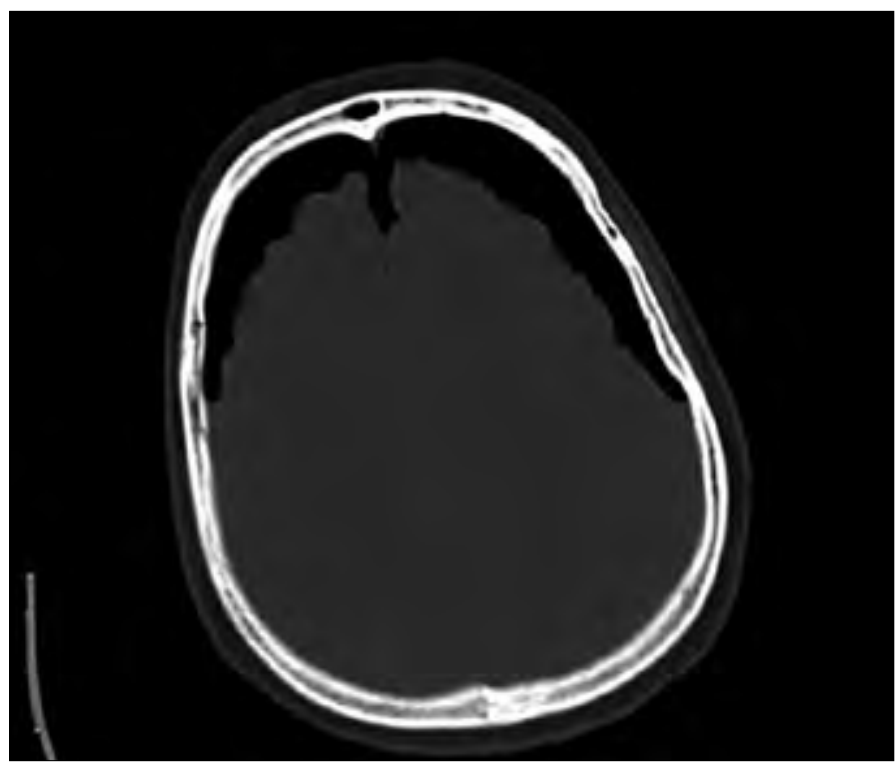

Figure 2. Bifrontal and intrahemispheric pneumocephalus

Correspondence to: Serkan Emre Eroğlu e-mail: drseroglu@gmail.com 


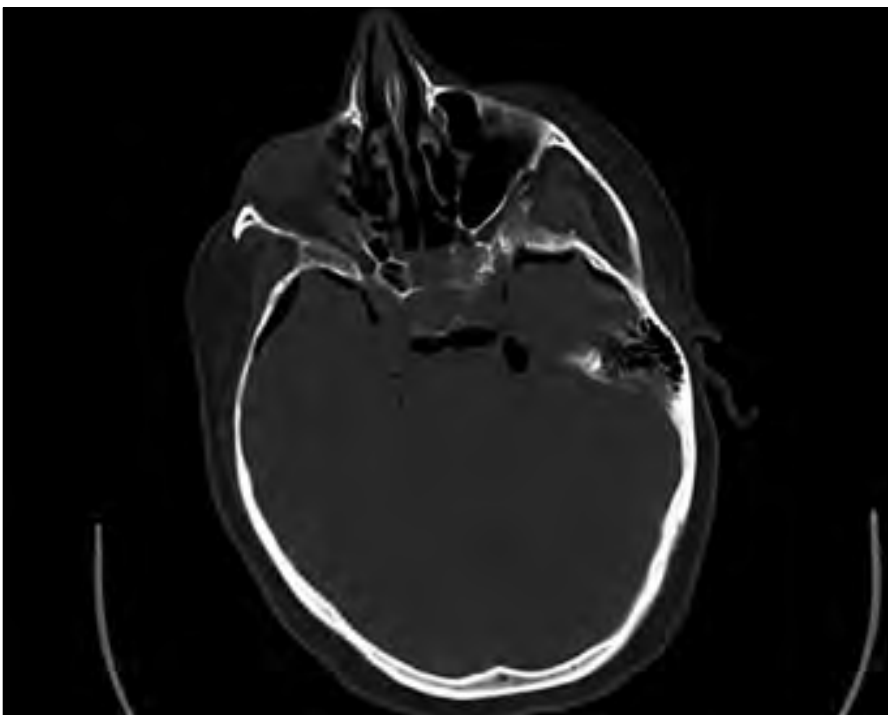

Figure 3. Parasellar pneumocephalus arrest. Early diagnosis and treatment are important because it is a life-threatening complication (3).

In conclusion, one cause of the occurrence of postoperative headache after neurosurgical procedures can be pneumocephalus. Urgent intervention is necessary to avoid tension pneumocephalus.

\section{References}

1. Goodwin CR, Boone CE, Pendleton J, Elder BD, Wei Z, Hsu W, et al. Pneumocephalus leading to the diagnosis of cerebrospinal fluid leak and esophageal perforation after cervical spine surgery. J Clin Neurosci 2016: 26: 141-2. [CrossRef]

2. Banu MA, Szentirmai O, Mascarenhas L, Salek AA, Anand VK, Schwartz $\mathrm{TH}$. Pneumocephalus paterns following endonasal endoscopic skull base surgery as predictors of postoperative CSF leaks. J Neurosurg 2014: 121: 961-75. [CrossRef]

3. Biyani N, Silbiger A, Ben-Ari J, Constantini S. Postoperative brain stem tension pneumocephalus causing transient locked-in syndrome. Pediatr Neurosurg 2007; 43: 414-7. [CrossRef] 